\title{
Nuevas Dinámicas del Poder Naval en el Siglo XXI: la competencia por el control en el espacio marítimo ${ }^{1}$
}

\author{
New Dynamics of Naval Power in the 21st Centu- \\ ry: Competition for Sea Control
}

Mariana Altieri ${ }^{2}$

Resumen: Este artículo, estudia la dinámica del poder naval en el contexto internacional del Siglo XXI. En él se analiza de qué forma la competencia por el reacomodamiento de poder mundial, entre los actores statuquistas y revisionistas del sistema internacional, se plasma en la disputa por el ámbito marítimo. Se sostiene que, en el marco de la decadencia de Estados Unidos como poder naval hegemónico y el ascenso de nuevos poderes navales, el espacio marítimo se ha convertido en la gran zona de fractura de este tiempo.

Palabras Clave: Poder Naval, Statuquistas, Revisionistas, Espacio Marítimo, Espacios Comunes del Globo, Estados Emergentes, A2/NA,

Abstract: This paper analyzes the dynamics of naval power in the international context of the 21st Century. It addresses how the competition for the rearrangement of global power between the statuquist and revisionist actors of the international system is reflected in the dispute over the seas. It is argued that, the United States' hegemonic naval power being on the decline and new naval power being on the rise, the maritime space has become the great fracture zone of the present.

Key Words: Sea Power, Statuquist, Revisionist, maritime environment, Global Commons, Rising States, A2/AD.

\footnotetext{
${ }^{1}$ Recibido: 31/07/2018. Aceptado: 01/11/2018

${ }^{2}$ Licenciada en Ciencia Política de la Universidad de Buenos Aires, Magister en Estrategia y Geopolítica por la Universidad de La Defensa Nacional, Docente e investigadora de ambas instituciones y de la Universidad Provincial de Ezeiza. Directora del Grupo de Investigación "Repensando el Orden Mundial desde el Sur" Email: marianaltieri@gmail.com
} 


\section{Introducción: el Ambiente Estratégico}

Este artículo, analiza la dinámica del poder naval en el contexto internacional del Siglo XXI. Se parte de la concepción de que el Siglo XXI atraviesa un momento de desconcentración y dispersión del poder en el marco de una etapa de transición hacia una nueva reconfiguración del orden mundial, que se traduce en una dinámica de competencia entre los actores del sistema internacional.

Esta reconfiguración se pone de manifiesto por un lado, por la decadencia del liderazgo mundial de los Estados Unidos, - visible tanto en la pérdida de prestigio como líder global, así como en el lento pero firme declive de su poder material- y por otro lado, en función del ingreso en la arena de la política internacional de Estados emergentes en ascenso y potencialmente revisionistas del statu quo. A tal fin, se asume como válida la conceptualización de Randall Schweller (2011) de que el sistema internacional se encuentra atravesando una fase de "deslegitimación" del hegemón mundial y de desconcentración de poder ${ }^{3}$, lo cual fomenta la competencia por el control del espacio marítimo, como uno de los grandes espacios comunes del globo.

Siguiendo a Battaleme (2013) se ha considerado que el reacomodamiento de poder mundial se plasma directamente en la proyección y ejercicio del poder sobre un espacio determinado y se manifiesta principalmente en la competencia por el acceso de los grandes espacios comunes. En este sentido, el mar representa hoy, no solo uno de los espacios comunes de mayor dinamismo, sino que se trata del ámbito donde se reproduce el sistema a través del intercambio de las comunicaciones y del comercio- y donde, por ende, se están manifestando más visiblemente las disputas por el control, específicamente en lo que hace a la proyección de poder y la capacidad de negar o no el acceso al adversario.

En base al abordaje teórico propuesto y siguiendo al definición de Mearsheimer (2001) se estudia la posición de los grandes poderes ${ }^{4}$ en el escenario de reacomodamiento del poder mundial, clasificando a los Estados como statuquistas, proclives a sostener el sistema en su conformación vigente, y revisionistas, inconformes con la situación actual que contribuyen a su alteración buscando aumentar sus beneficios; observando a su vez, si estos Estados son proclives a tomar riesgos para mantener o modificar el sistema. Siguiendo esta línea conceptual, se ha clasificado a los Estados como statuquistas o revisionistas en función del alineamiento o no con la potencia hegemónica vigente, adoptando la definición de Mearsheimer (2001) y de Schweller (2014) de que los Estados propenderán al balance 5

\footnotetext{
${ }^{3}$ Schweller (2014) elabora un ciclo explicativo de la dinámica del orden mundial que consta de cinco fases: 1. Orden estable, 2. Desconcentración de poder y deslegitimación del poder hegemónico, 3. Formación de alianzas de los emergentes, 4 . Crisis y guerra por la hegemonía, 5 . Nuevo sistema, sistema renovado. La fase de deslegitimación es la respuesta a la erosión de la fase de liderazgo. La deslegitimación ocurre después de que el Hegemón (o poder unipolar) ha comenzado un declive relativo. (Schweller \& Pu, 2011)

${ }^{4}$ Es importante señalar que la selección de casos de estudios responde a un recorte metodológico que busca limitar el universo para darle mayor profundidad y factibilidad. Por esta razón se han seleccionado los grandes actores internacionales que son poderes navales en la actualidad, y que tiene incidencia a nivel global.

${ }^{5}$ Para Schweller (2011), al igual que para el realismo ofensivo, el elemento que define el comportamiento de un Estado es la búsqueda de ganancias por sobre la seguridad. Esta asunción implica la postulación de que los grandes poderes solo se convertirán en Estados revisionistas si consideran que este comportamiento les concederá una mejor posición en el sistema internacional. Mearsheimer (2001, pág. 28) esta-
} 
al plegamiento ${ }^{6}$ en función de sus propios intereses, priorizando la búsqueda de beneficios por sobre la seguridad. Para ello se observará si los Estados desarrollan un comportamiento de "sostenedores" -supporters-, "saboteadores" -spoilers- o "evasores" -shirkers-, respecto del mantenimiento orden internacional vigente ${ }^{7}$.

\section{La competencia por el poder naval a escala global}

Parece más probable que la importancia histórica del mar aumente más que decline en el futuro inmediato. El valor de sus recursos crecerá a medida que aumenta la población mundial, y como medio de transporte el mar continuará siendo central para el sistema de comercio mundial, del cual todo depende. (Till G. , 2007, pág. 452)

Como se desarrolló previamente el factor geográfico determina no sólo la ubicación de los Estados sino también sus áreas de proyección de poder, sean espacios terrestres o marítimos. Es en este último tipo de escenarios donde se juegan las relaciones internacionales del presente siglo: los océanos como teatro $y$, sobre todo, como objeto de conflicto interestatal ${ }^{8}$.

En el sistema cerrado de Mackinder $^{9}$ (2010), que retoma Kaplan (2012), los grandes poderes vuelven sus intereses hacia lo que se denomina "espacios comunes", tres de ellos son espacios geográficos concretos: el aire, el mar y el espacio ultraterrestre, y el cuarto es un derivado de desarrollo tecnológico: el ciberespacio. Battaleme señala que "Estos espacios presentan la característica de que no están definidos por líneas fronterizas fijas, pudiendo pertenecer sin que eso impida que puedan ser explotados (por desinterés, incapacidad o por acuerdo), por otros actores". (Battaleme, 2013, pág. 4) En los espacios comunes la soberanía se ejerce mediante la ocupación y el uso. En el caso del

blece que existen diferentes estrategias que los Estados persiguen con el objetivo de acrecentar o mantener su poder. Entre ellas el "Balance de Poder" es una de las principales estrategias para sostener el statu quo. A su vez, la propensión al riesgo de cada uno de ellos definirá si son más o menos arriesgados a la hora de tomar definiciones en su política exterior.

${ }^{6}$ Schweller (2004) entiende al plegamiento como una forma de realimentación positiva que desequilibra el sistema, ya que implica aliarse siempre con el más fuerte, sea el actor statuquista o revisionista, mientras que el balance de poder es una realimentación negativa que lo equilibra.

${ }^{7}$ Schweller (2011) sostiene que en un sistema unipolar los poderes emergentes, se enfrenta a tres cursos de acción posibles: el primero es comportarse como sostenedores -Supporters- del sistema, entendiendo que ascender al status de potencia implica contribuir al mantenimiento del sistema (bajo el supuesto de que acatar lar normas vigentes conllevara un aumento de su prestigio y reconocimiento por parte de las otras potencias). El segundo curso de acción es convertirse en Saboteadores- Spoilers-, desafiando las normas del sistema de manera abierta. Y en tercer lugar optar por un comportamiento de "evasores"Shirkers-, comportase como un jugador del sistema vigente, sin desafiarlo abiertamente, pero sin asumir los costos de este mantenimiento (los cuales recaen en el Hegemón actual)

${ }^{8}$ El eje de este trabajo se ocupa de la dinámica interestatal sin embargo es preciso señalar el enorme peso de los actores no estatales en el espacio marítimo.

${ }^{9}$ Kaplan (2012) fundamenta su análisis en las consideraciones de Halford Mackinder del mundo como un "sistema cerrado", Mackinder construye esta conceptualización entendiendo que: "Mientras la cristiandad medieval "se concentraba en una región reducida y amenazada por la barbarie externa», la era colombina la era de los descubrimientos - vio la expansión de Europa hacia otros continentes a través de los océanos (...). Sin embargo, de la época actual en adelante, en la era poscolombina (...), "tendremos que volver a tratar con un sistema político cerrado», y esta vez uno de "ámbito mundial»". (Kaplan 2012, 82) 
espacio marítimo el océano es ocupado por los Estados que detentan esa capacidad a través del poder naval.

Si bien Morgenthau (1987) solía atribuir al océano la característica de aislamiento; lo cierto es que, con la globalización, el mar es un espacio de conexión y apertura hacia el resto del sistema internacional. "El aspecto más visible que nos ofrece primeramente el mar, al considerarlo desde el punto de vista político social, es el de un gran camino, o, gandul mejor dicho, una vasta extensión de propiedad común por la que el hombre puede trasladarse en todas direcciones" (...). (Mahan, 1946, pág. 37)

La importancia geoestratégica del espacio marítimo abarca gran cantidad de elementos que resultan fundamentales para la conformación del poder nacional: además del control y acceso a sus recursos -minerales, hidrocarburíferos, polimetálicos, ictícolas etc.-; posicionarse desde el océano favorece el control de las rutas comerciales y brinda la posibilidad de proyectar poder hacia terreno firme.

El británico Geoffrey Till, considera que son cuatro los atributos que definen el mar como escenario estratégico: como medio de información y de expansión de ideas, como medio de transporte e intercambios, como fuente de recursos, y como medio de dominio. "Estas características son las que configuran al mar como elemento central de las relaciones internacionales en el siglo $\mathrm{XXI}$, tanto en materia de comercio internacional como a la eterna lucha por el poder mundial”. (Till G. , 2007, pág. 40)

El poder naval nunca es absoluto, sino que se mide en términos relativos al de las otras armadas. Till (2007), sostiene que el verdadero poder es tener la capacidad de ejercer el "control del Mar" ${ }^{10 "}$ por el tiempo y en el lugar determinado para cumplir los fines propios. La otra opción estratégica del "control del mar" es la capacidad de "negación del mar", que implica impedir que un oponente utilice un área del mar para sus propósitos.

En esta línea, las funciones clásicas del poder naval son: asegurar el control del mar, proyectar poder tanto en paz como en guerra, atacar y defender el comercio marítimo (directa e indirectamente) y mantener el buen orden en el mar.

Si se analizan los puntos centrales de la estrategia naval de los Estados Unidos queda de manifiesto que - como corresponde a la potencia naval hegemónica- contienen las funciones clásicas y señalan, además, algunos conceptos nodales para comprender el poder naval del siglo XXI: control del mar, proyección de poder, seguridad marítima y presencia avanzada $^{11}$. ( US Navy, 2007), (US Navy, 2015)

En línea con los preceptos de la teoría, el objetivo de "control del mar" es en realidad, la pre condición que posibilita la prosecución del resto de los objetivos planteados. El control del mar se consigue a través del mantenimiento de la fuerza naval necesaria,

\footnotetext{
${ }^{10}$ Es importante señalar respecto al concepto del "Control del Mar", que el mismo está vinculado al concepto originalmente planteado por los grandes teóricos del Poder Naval: el "Dominio del Mar". Sin embargo el término "Dominio del Mar" ha dado lugar a tantos debates respecto de la medida de dicho domino que la armada de Estados Unidos, durante la guerra fría, dio lugar a un nuevo concepto remplazando "dominio del mar" por el actual "control del mar" que hace énfasis en que dicho control o dominio se persigue en función de otros objetivos, y se ejerce circunscripto geográfica y temporalmente. Se "controla el mar" en áreas limitadas por periodos de tiempo definidos, pero en esencia nunca se lo domina.

${ }^{11}$ la CS21R del 2015 estableció cinco funciones principales para la armada: acceso a todos los dominios, disuasión, control del mar, proyección de poder y seguridad marítima. (US Navy 2015)
} 
tanto en cantidad como en calidad, para controlar el mar en los espacios de interés vital para la nación.

Como se señaló previamente, el poder naval no es solamente el ejercicio del control del mar, (aunque eso, evidentemente, es un requisito previo). "Es también la capacidad de influir en el comportamiento de otras personas o cosas a través de lo que uno hace o no desde el mar". (Till G. , 2007, pág. 26) La capacidad de proyectar el poder naval a tierra, abarca muchas definiciones que son en realidad formas diferentes de su aplicación, -guerra anfibia, operaciones combinadas, operaciones tierra/mar, ataques a territorios desde el mar, etc. La proyección de poder naval involucra el uso de las fuerzas armadas provenientes del mar para influir en los eventos en tierra. Su gama va desde invasiones a un territorio en un extremo del espectro, hasta incursiones pequeñas de hostigamiento y la capacidad de realizar bloqueos en el otro. En este extremo se mezcla con las formas más coactivas de la diplomacia naval.

La diplomacia naval es la posibilidad de utilizar las armadas con fines políticos definidos por la política exterior sin la intensión o necesidad de desatar un conflicto armado. Esta, según específica Till, abarca todas las formas de influencia del poder marítimo ${ }^{12}$ en la política exterior de un Estado, sin llegar al uso de la fuerza naval. La misma puede ejercer de "coacción" o "disuasión"13.

Volviendo a los puntos de la estrategia naval estadounidense, el "control del mar" requiere a su vez la presencia efectiva de la armada en aquellos lugares que se pretende controlar. Por ello otro de los objetivos fundamentales para una armada de alcance global es la "presencia avanzada", esto es mantener la flota posicionada geográficamente de forma tal que permita despliegues reactivos de forma efectiva.

Mientras que su mera presencia estacionaria funciona como diplomacia naval, la presencia avanzada permite una de las características principales de la proyección de poder a tierra, especialmente en la política internacional Estadounidense, "las operaciones expedicionaria" Según Till (2007) las operaciones expedicionarias han adquirido una mayor preminencia en la era de la post guerra fría debido al incremento del desorden, y al auge de las "operaciones de mantenimiento y de imposición de la paz" Por supuesto, esta presencia global es lo que permite de alguna manera cumplir con el objetivo de garantizar la seguridad de los mares y el principio madre de la política naval estadounidense: asegurar la libre navegación y la seguridad de las líneas de comunicación. En esta línea, el despliegue de "súper fortalezas flotantes" implica mudar sus recursos y bases en países aliados a islas propias o a alta mar, a los efectos de: "Mantener un rol de disuasión efectivo capaz de responder a las necesidades de seguridad y mantenimiento del orden ya entrado el siglo XXI, independientemente de los socio y aliados regionales (...)

\footnotetext{
${ }^{12}$ En sus obras Till utiliza la acepción "poder marítimo", concepto que se define como abarcativo del poder naval (considerado como estrictamente militar) pero más amplio dado que engloba los aspectos no militares del uso del mar.

${ }^{13}$ Las operaciones de compulsión naval esta dirigidas a compeler a un adversario para que haga algo que no quiere hacer, mediante el uso coactivo de fuerzas basadas en el mar. Por ejemplo, una forma de compulsión no letal es la interceptación marítima. (Till 2007, 356) Por otro lado, la disuasión naval, implica la utilización de las fuerzas navales para disuadir a un adversario de que no haga algo mediante la exhibición de los costos probables. (Till 2007, 363)
} 
cumpliendo con la premisa del repliegue y la reorientación a estrategias de balanceador extra regional" (Battaleme, 2013, pág. 4)

La estrategia marítima de los Estados Unidos, sintetizando, propone centrar los esfuerzos navales en tres áreas: el control del mar para garantizar que Estados Unidos pueda operar libremente por los océanos; la proyección del poder para desplegar rápidamente y sostener eficazmente una fuerza capaz de batir a cualquier adversario en cualquier punto del globo; y la seguridad marítima para proteger el tráfico marítimo mundial de cualquier acto de terrorismo, piratería, crimen organizado o ataque deliberado y combatir cualquier actividad ilícita que pueda producirse en el mar y en la región costera.

A este respecto, en un artículo reciente de la Revista Foreign Affairs, aparecieron declaraciones del Secretario de Defensa James Mattis, acerca del movimiento de la armada estadounidense en al Asia pacifico "No buscamos la libertad de navegación solo para América... es libertad para todas las naciones, grandes y pequeñas, que necesitan transitar esas aguas para su propia prosperidad y tienen todas las razones para hacerlo" (Glaser \& Poling, 2018, pág. 1) Es decir que Estados Unidos se sigue presentando asimismo como el garante de buen orden en el mar, y demandando el control en todo espacio marítimo, como potencia marítima dominante. Más allá de que haya un esfuerzo por compartir algunas responsabilidades con los aliados y socios, con el objetivo de achicar sus gastos y concentrarse donde debe garantizar el mantenimiento de su influencia frente a posibles competidores.

\section{Statuquistas y Revisionistas en el Mar}

El Estado del poder naval no es inmutable y se haya íntimamente relacionado con las reconfiguraciones del escenario internacional. Actualmente, la armada estadounidense es la única capaz de ejercer el poder naval de manera global -en todos los océanos. Sin embargo, el declive de la unipolaridad tiene su correlato en lo que respecta al control del mar como potencia marítima dominante. Esto se debe a varios factores, pero principalmente al surgimiento de potencias navales medias revisionistas del status quo en el mar. En otras palabras, los Estados en ascenso están desarrollando su poder naval con intenciones revisionistas.

Kagan señaló hace algunos años que Estados Unidos era el poder naval dominante debido a que ninguna otra armada podía darse el lujo de competir con él, y por ende permitían que la Marina de los Estados Unidos cumpliera el rol de garante de las vías navegables internacionales. Aunque... "En un mundo más genuinamente multipolar, sin embargo, no lo haría. Las naciones competirían por la dominación naval por lo menos en sus propias regiones y posiblemente más allá ${ }^{14 \prime \prime}$. (Kagan, 2007, pág. 9)

El escenario naval expresa dos cambios fundamentales que se condicen con las transformaciones en el sistema internacional. En primer lugar, la trasformación de grandes países continentales en potencias navales, China es el mayor ejemplo, pero también

\footnotetext{
${ }^{14}$ Texto Original en Inglés, Traducción propia.
} 
podríamos decir lo mismo de Rusia ${ }^{15}$, India, Japón, así como de otras potencias regionales medianas ${ }^{16}$, como, Brasil, Turquía e Irán, entre otras, que también están invirtiendo en potenciar y/o renovar sus fuerzas navales-. Este surgimiento de nuevas armadas con capacidades no solo costeras sino oceánicas pone de manifiesto su carácter revisionista, en razón de que el acceso a los océanos permite proyectar poder y otorga libertad de acción.

En segundo lugar, asistimos a una transición entre un garante global de las líneas de comunicación marítimas hacia un control ejercido por actores navales regionales, ya sea de manera subsidiaria y en acuerdo con los Estados Unidos, como en función de la disputa por el control del mar con las potencias navales medias revisionistas.

Respecto a las responsabilidades compartidas con los aliados y socios, es importante destacar que la marina británica continúa siendo un eje fundamental en las estrategias de defensa y de política exterior para el Reino Unido ${ }^{17}$ que mantiene su status de potencia naval, en asociación con Estados Unidos como potencia marítima dominante. De hecho, Gran Bretaña proporciona un conjunto de posiciones de ultramar de relevancia a la OTAN, especialmente en el Atlántico Sur, y patrulla la seguridad de las líneas de comunicación y comercio en esa área de manera subsidiaria a Estados Unidos.

A su vez, en la Estrategia de Seguridad Marítima, se establece que el Reino Unido ejercerá todas sus influencias para mantener y fortalecer el sistema internacional que rige el ámbito marítimo, debido a que en el mismo se sustenta la seguridad y prosperidad tanto del sistema Internacional como del propio Reino Unidos. A este respecto, la Armada Real Británica define la "presencia marítima" como la capacidad disponible al gobierno de su majestad para influir en eventos políticos y militares a nivel mundial por medio de despliegues marítimos. Esto incluye la capacidad de proyectar una fuerza militar balanceada que pueda mantenerse durante periodos prolongados, preparada para una rápida respuesta a través del espectro de tareas militares. Aclarando que las mismas constituyen una forma de diplomacia naval, y que pueden desarrollarse de forma tanto "simbólicas" como "coercitivas"

En este sentido, es posible clasificar al Reino Unido como una potencia naval de carácter statuquista con una sólida alianza a la potencia hegemónica, es decir, un miembro responsable del sistema - Sostenedor en términos del Schweller- que apoya la distribución de poder actual, que ejerce y comparte.

Sin embargo, si en la dinámica del Atlántico Sur la potencia Naval, el reino Unido, ejercer de garante de la seguridad marítima de manera subsidiaria a la potencia naval global, Estados Unidos; lo que sucede en otras zonas más conflictivas del océano, como el Mar de la China, es todo lo contario.

\footnotetext{
${ }^{15}$ Si bien la política naval rusa en los tiempos de URSS, una vez abandonada la política costera de los primeros años, la llevo a crear una gran armada, nunca dejo de pensarse a sí misma como un poder terrestre.

${ }^{16}$ Vale la pena aclara que en este análisis no se está haciendo referencia a los poderes navales regionales medianos en general, como podría ser el caso de Chile en América del Sur, sino a las potencias regionales, con aspiraciones de gravitación global, que están invirtiendo recursos en sus armadas.

${ }^{17}$ La seguridad de las líneas de comunicación y específicamente del tráfico comercial es una de las preocupaciones históricas del Reino Unido.
} 
El statu quo marítimo planteado por la unipolaridad estadounidense tendió a basarse en la proyección global de poder a partir del sostenimiento de un comando del espacio común, del cual participaban los aliados y se excluía a los adversarios. La decadencia de la unipolaridad pone en entredicho este comando y da lugar a que las potencias emergentes, que cuentan con poderes navales medianos y en crecimiento, evalúen estrategias que comparen sus medios y capacidades con las del poder naval preponderante. Estos planteamientos se plasman en las nuevas doctrinas navales que dan cuenta de una geoestratégia proclive a revisar el statu quo del mar, que se traduce en inversión en el sector y fortalecimiento material de las armadas.

Kaplan sostiene que uno de los indicadores de la enorme transformación en la dinámica del espacio marítimo, es que: "Ahora sean los estrategas indios y chinos los que leen a Mahan con avidez; ellos, muy por delante de los Estadounidenses, son los nuevos mahanianos, los que construyen flotas concebidas para enfrentamientos armados en el mar, mientras que las armadas europeas contemplan el poder marítimo solo en términos policiales" (Kaplan, 2012, pág. 130)

En esta línea actualmente, se ha puesto en boga lo que se conoce como capacidades "Anti Acceso" y de "Negación de Área" -A2/NA ${ }^{18}$. En 2003, el Centro para Evaluaciones Estratégicas y Presupuestarias -CSBA ${ }^{19}$ - definió como "Anti-Acceso" a las acciones del adversario que inhiben el movimiento militar en un teatro de operaciones, y como "Negación de Área", a las actividades capaces de negar la libertad de acción dentro de las áreas bajo control del adversario ${ }^{20}$. (Krepinevich, Watts, \& Work, 2003, pág. 45)

Battaleme (2013) pone de relieve esta dinámica entre la proyección de poder naval tradicional de las armadas hegemónicas, que buscan mantener el acceso abierto para ello y eventualmente cerrarlo a un posible competidor, y entre los poderes ascendentes que persiguen, no solo evitar esto sino cerrar el espacio común a la proyección de poder de los grandes poderes navales; ya que dificultar o negar el acceso los refuerza en su rol como retadores ${ }^{21}$ ascendentes.

Como se señaló de forma precedente, una de las características del escenario naval actual es que grandes poderes terrestres, que además son potencias emergentes potencialmente revisionistas del statu quo, están tornando sus recursos materiales hacia el mar en un esfuerzo por volverse potencias navales. La novedad de estos planteamientos está relacionada a que las armadas de potencias medias, o de poderes navales incipientes, destinan recursos específicamente en la concreción de estas capacidades, aplicando nuevas tecnologías o tecnologías disruptivas que pueden garantizar capacidades A2/NA sin demandar inversiones inviables (a través de tecnologías cibernéticas, satelitales, o incluso mediante el minado de los fondos submarinos de las zonas adyacentes a la tierra).

En este sentido, es posible inferir que la obtención de capacidades A2/NA es un fin perseguido por las potencias medias como instrumento de revisionismo en el mar, en relación a que son específicamente plausibles de ser utilizadas por poderes navales inci-

\footnotetext{
${ }^{18}$ A2/AD en inglés: Anti Access y Area Denial

${ }^{19}$ Sigla de la abreviatura en ingles de Center for Strategic and Budgetary Assessments

${ }^{20}$ En este sentido es dado señalar que el ejercicio del control del mar por parte de las potencias navales implica en sí mismo este tipo de capacidades.

21 "Challanger" también puede traducirse como "desafiantes"
} 
pientes, que no detentan la capacidad de control del mar, ni flotas de aguas profundas, pero tiene la intención de disputar o dificultar el dominio del adversario.

\section{China, la mejor expresión de "A2/NA"}

Durante la mayor parte de su historia milenaria, el imperio celeste prácticamente le dio la espalda al mar, y a todas sus posibilidades. China fue víctima y no ejecutora del poder naval, y especifícame de la proyección de poder naval a tierra, con las guerras del Opio como uno de los mayores ejemplos de dominación de un gran poder terrestre por una potencia naval. No obstante, se ha establecido ya que, si algo está cambiando en las tendencias navales de los albores del nuevo milenio, es que las grandes potencias territoriales están, esta vez, cada vez más interesadas en el mar. "Gracias a su favorable situación en tierra, China es ahora libre para trabajar en la creación de una gran armada (...) en el siglo veintiuno China proyectará poder duro principalmente a través de su armada"22. (Kaplan, 2010, pág. 33)

La Estrategia Militar China que vio la luz en el año 2015, habla de una "defensa activa" y del rejuvenecimiento de China desde el "Desarrollo Pacífico" -reconversión nominal del concepto anterior de "Ascenso Pacífico" El mismo documento establece que:

Los mares y océanos se apoyan sobre la paz duradera, la estabilidad y el desarrollo sostenible de China. La mentalidad tradicional de que la tierra es más importante que el mar debe ser abandonada, ya que gran importancia debe atribuirse a la gestión de los mares y océanos y la protección de los derechos e intereses marítimos. Es necesario para China desarrollar una estructura militar marítima moderna acorde con sus intereses de seguridad y de desarrollo nacionales, para salvaguardar su soberanía nacional y los derechos e intereses marítimos, proteger la seguridad de sus SLOCs ${ }^{23}$ estratégicas e intereses en el extranjero, y participar en la cooperación marítima internacional, a fin de proporcionarse el soporte estratégico necesario para convertirse en una potencia marítima ${ }^{24}$ (State Council Information Office People's Republic of China, 2015, pág. 3)

La defensa activa es el concepto estratégico que prepara a las fuerzas para tres misiones clave: mantener al enemigo fuera de los límites y resistir toda agresión desde el mar; proteger su soberanía territorial; y salvaguardar la unidad y los derechos marítimos nacionales. Más allá de su discurso oficial sobre el "ascenso pacífico" el gobierno chino ha tomado medidas y ha realizado acciones muy claras que denotan hasta qué punto está disputando por ejercer plenamente la influencia que "le corresponde" en su zona. "China afirma que su ascenso está previsto para ser pacífico, pero sus acciones cuentan una historia diferente: el de una potencia revisionista en la búsqueda de dominar el Pacífico occidental" (Krepinevich A. J., 2015, pág. 78) ${ }^{25}$.

China ya no se siente satisfecha con el statu quo de la región, y está empezando a empujar un cambio. La expansión de sus intereses la lleva inevitablemente a la necesidad

\footnotetext{
${ }^{22}$ Texto Original en Inglés, Traducción propia.

${ }^{23}$ "SLOCS" en la abreviatura de "Sailors Lines of Comunications": líneas de comunicación marítima.

${ }^{24}$ Texto Original en Inglés, Traducción propia.

${ }^{25}$ Texto Original en Inglés, Traducción propia.
} 
de expansión de su esfera de influencia, y conduce al gigante asiático en un rol clave en la fase de deslegitimación de la potencia hegemónica, que no es de disputa abierta, sino de avance firme "lento pero seguro". La China de hoy no desafía, aun, el orden internacional, sino que está concentrada en ordenar su influencia en su propio patio trasero, es decir en consolidarse cómo Hegemón en la región más dinámica del mundo de hoy. Sin embargo, esa postura por si misma desafía la hegemonía estadounidense: "La intención de Beijing no es provocar un conflicto, sino más bien cambiar poco a poco la realidad política de la región mediante la expansión de su zona de amortiguación marítimo y asegurar sus rutas comerciales. Sin embargo, pocos de estos cambios pueden quedar sin ser desafiados, agregando una capa de incertidumbre para el futuro de Asia Oriental ${ }^{26 \prime \prime}$ (Stratfor, 2014).

Es quizás la más notable expansión del poder militar desde los EE.UU. preparándose para la segunda guerra mundial. China se ha basado en su economía creciente para proporcionar aumentos de dos dígitos anuales en los presupuestos militares; y se han aprovisionado de una serie de avanzados aviones a reacción, misiles antiaéreos, radares anti-aéreos y buques antisubmarinos, y minadores destinados a impedir el acceso a las aguas y los cielos chinos, y por supuesto portaviones.

"Desafortunadamente, es difícil conciliar la idea de que tal voluntad pueda existir en Beijing con la acumulación militar continuada y las tácticas coercitivas vistas a lo largo de 2017. La conclusión más optimista es que el gobierno de China tiene dos mentes en el Mar Meridional de China: dispuesto a flirtear con esfuerzos diplomáticos mientras simultáneamente busca el dominio sobre sus vecinos a través de medios militares y paramilitares." (Poling 2018, pág. 1)

En este ajedrez marítimo, la armada china ve poco más que problemas en la llamada "primer cadena de islas ${ }^{27}$ ": la península de Corea, Japón (incluyendo las Islas Ryukyu que están en conflicto), Taiwán, Filipinas, Indonesia y Malasia. La República Popular China concibe a la primera cadena de islas como el área que debe asegurar e inhabilitar como campo de acción del enemigo. El concepto aumenta los temores chinos de ser rodeados por fuerzas Estadounidenses, y enfatiza la importancia geográfica y estratégica de Taiwán ${ }^{28}$. Si entrar en los detalles de la compleja situación del Asia Pacifico en general, y del Mar del Sur de la China en particular, podemos señalar que los movimientos chinos se han vuelto cada vez agresivos en lo que respecta lo que considera sus legítimas demandas en la zona pero estos movimientos no se han encontrado con una respuesta efectiva -o contundente- por parte del resto de los actores de la zona, incluida la potencia extra regional: "En este sentido "el Departamento de Defensa de los EE. UU. Dio un paso importante a (...) al desvincular a la Armada China de los ejercicios navales del Borde del Pacífico 2018, los mayores ejercicios navales multilaterales en el mundo, en lo que un portavoz del Pentágono denominó una "respuesta inicial" a la continua militarización de China en el Mar del Sur de China." (Glaser y Poling 2018)

\footnotetext{
${ }^{26}$ Texto Original en Inglés, Traducción propia.

${ }^{27}$ La primera cadena de islas se refiere a los archipiélagos de la costa continental de Asia oriental, principalmente compuesto por las islas Kuriles, el archipiélago japonés, las islas Ryukyu, Taiwán, el norte de Filipinas y Borneo; de la península de Kamchatka a la península de Malaya.

${ }^{28}$ La segunda cadena de islas es la que comunica con el Océano "abierto" está formada por las islas Ogasawara y las islas volcán de Japón, Guam y las islas Marianas que son territorio de los Estados Unidos.
} 
Sin embargo, al mismo tiempo que incrementa su armada, China ha trabajado dentro del actual sistema internacional para expandir su economía y aumentar su visibilidad y estatus como un actor político global, evitando al mismo tiempo las acciones que desafían directamente la hegemonía estadounidense. Apoyándose en los canales institucionalizados existentes, ha buscado aumentar su influencia política y prestigio a través de la participación activa en el orden existente, actuando como sostenedora del orden en su ascenso pacifico.

Para Schweller (2014), la asertividad china vista bajo los lentes del realismo clásico, sería un resultado racional al principio por el cual "las naciones expanden sus intereses políticos al aumentar su poder relativo"; es decir, los intereses de un Estado crecen al mismo ritmo que su poder. Como se señaló, a medida que el poder de un Estado aumenta, ese Estado tendrá la tentación de tratar de aumentar su control sobre el medio circundante con el fin de aumentar su propia seguridad, tratará de ampliar su zona de influencia y, sobre todo, pretenderá modificar el sistema internacional de conformidad con su conjunto particular de intereses.

Debido a que dos potencias hegemónicas no pueden existir simultáneamente en la misma región, la competencia sino-estadounidense por la supremacía en la región de Asia y el Pacífico posiblemente continuara en aumento hasta que haya una conclusión decisiva. Si bien el liderazgo chino todavía no han desafiado directa y abiertamente la hegemonía Estadounidense, ha comenzado a pensar más allá del orden existente desarrollando estrategias que sabotea el orden establecido. Al igual que Estados Unidos buscó el dominio sobre el hemisferio occidental un siglo y medio atrás, China pretende dominar su propio "patio trasero" especialmente en el sudeste de Asia, donde Estados Unidos ha sido el balanceador extra regional ${ }^{29}$ desde la segunda guerra mundial.

La estrategia china opera a lo largo de dos dimensiones: las formas en que China explota el orden actual y su pensamiento más allá de ese orden. "Para hacer frente al orden existente, China acomoda de forma pragmática la hegemonía Estadounidense, por un lado, mientras que, por otro, cuestiona la legitimidad de esa hegemonía ${ }^{30 "}$. (Schweller \& Pu, 2011, pág. 52)

Es importante señalar que la negación del espacio marítimo implica capacidades de largo y corto alcance. La primera implica poseer fuerzas de submarino de ataque y misiles antibuques, misiles de crucero e inclusive basilítiscos - como el recientemente puesto en servicio en servicio por la armada china denominado oficialmente DF-21D pero popularmente conocido como el misil "anti-portaviones". (Battaleme, 2013, pág. 12) La segunda -más cercana a las costas-, implica el minado marino, submarinos costeros, y botes de ataque rápido o patrullas misilísticas. (Krepinevich, Watts, \& Work, 2003)

Además de sus fuerzas de combate aéreo y naval, las capacidades de A2/NA chinas ahora se extienden mucho más allá de los dominios tradicionales de aire, mar y tierra. Esto incluye el desarrollo de los medios para desorientar los sistemas de mando y control del Pentágono, que dependen en gran medida del espacio (satélites) y el ciberespacio para coordinar las operaciones y la logística. Los ataques contra objetivos cibernéticos y

\footnotetext{
${ }^{29}$ El concepto en inglés: Off Shore Balancing puede traducirse también como "balanceador fuera de costas"

${ }^{30}$ Texto Original en Inglés, Traducción propia.
} 
espaciales estadounidenses amenazan con perturbar o completamente negar múltiples facilitadores de su proyección de poder.

La capacidad para proyectar su poder en el Pacífico Occidental y en el Golfo Pérsico permite a los Estados Unidos el acceso a zonas de interés vital. Capacidad que no había sido cuestionada efectivamente durante décadas. Las consecuencias del avance de las capacidades A2/NA chinas para la armada de los Estados Unidos incluye la amenaza de perder lugares de recalada de sus posiciones adelantadas. Esto se debe a la progresiva trasformación de China en una potencia naval, que manifiesta el propósito de asegurar su zona de influencia al menos a lo largo de la primera cadena de islas, y muy especialmente alrededor de las vías de comunicación, como el estrecho de Malaca. Mientras que Estados Unidos, balanceador extra regional y potencia mundial, se niega a retirarse y perder el acceso a la zona.

Es plausible concluir que, en el corto plazo, China busca una modificación gradual de hegemonía estadounidense sin un desafío directo, si bien su comportamiento alternado entre sostenedora y saboteadora es cada vez mas de balance, especialmente en lo que hace a los movimientos en el Mar de la China.

\section{Conclusiones}

Al conformar parte fundamental de los grandes espacios comunes del sistema cerrado, los océanos se han convertido en teatro, y objeto de conflicto interestatal, tanto entendidos como fuente de recursos, como medio de comunicación y transporte del comercio mundial, y específicamente como medio de dominio y de proyección de poder. Se ha definido al poder naval, a grandes rasgos, como la capacidad de una armada de ejercer el control de mar, entendido como la capacidad de garantizar la libertad de movimientos en el mar, y utilizarlo para sus propósitos mientras se niega su uso al adversario. Los grandes poderes proyectan poder más allá de sus fronteras geográficas y el poder naval es la herramienta para esa proyección en el resto del globo. Entendiendo que este poder se mide de forma relacional al poder naval de otras armadas, y que los intereses vitales de un Estado aumentan con su crecimiento y desarrollo. De allí las funciones clásicas del poder naval: asegurar el control del mar, proyectar poder hacia tierra tanto en paz como en guerra, atacar y defender el comercio y mantener el buen orden en el mar, es decir la seguridad de las líneas de comunicación y de las rutas comerciales. Sin embargo el desarrollo de capacidades A2/NA brinda la posibilidad de denegar el uso aunque no se detente el control del mar.

En el marco de la disputa por el control de los mares, la decadencia del poder mundial de Estados Unidos tiene un correlato en su rol como potencia naval global. Frente a la amenaza de perder el control o de ver limitado el alcance de su capacidad de proyección de poder Estados Unidos manifiesta propensión a tomar todos los riesgos necesarios a fin de sostener su supremacía. Esta definición lo lleva a desarrollar estrategias que le permitan independencia de movimiento basando su seguridad en sus propias fuerzas, como se puede apreciar en el objetivo de reforzar la presencia avanzada y en la implementación del pre posicionamiento naval a través de las "súper fortalezas flotantes". Es factible interpretar que esta definición responde a cierta preocupación por garantizar el acceso en algunos puntos de estrangulamiento claves para el tráfico marítimo. 
Si analizamos la forma en la que se comportan el resto de los jugadores geoestratégicos del mar, se observa que entre los grandes poderes statuquistas el Reino Unido comparte con Estados Unidos el control de las líneas de comunicación a nivel mundial específicamente el Atlántico Sur y el Océano Indico. En este sentido se manifiesta claramente en alineación con el statu quo vigente, con cierta propensión a tomar riesgos para mantenerlo, considerando que su poder e influencia disminuirían en cualquier tipo de reconfiguración del sistema.

A su vez, las potencias navales en ascenso buscan desarrollar capacidades A2/NA a fin de negar el acceso en aquellos lugares donde se encuentran sus intereses vitales. En la actualidad, China es el único poder en el mundo, con excepción de los Estados Unidos, que mantiene una acumulación militar a largo plazo, coincidente con su sostenido crecimiento económico, y por ende una inversión contante en mejorar sus capacidades navales. Se considera que la asertividad china está buscando asentar su posicionamiento. La consolidación de una postura abiertamente revisionista del statu quo en el Mar de la China, se alterna con una posición de sostenedora responsable en otros ámbitos internacionales. En este sentido, se considera que la República Popular China no está disputando abiertamente la hegemonía estadounidense a nivel mundial - por ahora. No obstante, el intento de asegurar su zona de influencia la lleva a desafiar el statu quo del poder naval en el Mar de la China, lo cual impacta en el statu quo del poder naval mundial. Al intentar vetar el acceso en la región más dinámica del mundo, China pone en juego la capacidad de Estados Unidos de seguir ejerciendo como garante global de las líneas de comunicación y del tráfico marítimo.

Por su parte, Estados Unidos ve claramente desafiada su hegemonía en función de lo cual debe definir una respuesta. Esta preocupación es fuertemente expresada por los grupos intelectuales vinculados a las cuestiones de defensa y preocupados por el desarrollo de estrategias acordes a mantener el control del pacifico.

Por ende, podemos afirmar que en el Mar de la China, como si fuera un escenario en miniatura de la contienda que se prevé en el resto de los océanos, la dinámica de la competencia entre los poderes statuquistas y revisionistas se plasma en la confrontación dos geoestrategias navales: Estados Unidos busca una estrategia que le permita responder a las amenazas y sostener el statu quo vigente, mientras que China reafirma sus aspiraciones revisionistas buscando crear una zona de amortiguación marítima entre su espacio vital y la proyección de poder estadounidense, basándose en el uso de capacidades A2/NA.

De qué forma continuará desarrollándose este conflicto en particular, y la gran dinámica de competencia mundial en general, esa por verse, sin embargo, se espera haber plasmado en este análisis algunos de los elementos fundamentales a tener cuenta para comprender el fenómeno del reordenamiento del espacio marítimo en ciernes.

\section{Bibliografía}

Battaleme, J. (2013). Cambiando el Status Quo de la Geopolítica Internacional: el acceso a los espacios comunes y las estrategias de negación de espacio y anti acceso. Cuadernos de Geopolítica, 1-21.

Glaser, B. S., \& Poling, G. (2018, Junio). Vanishing Borders in the South China Sea:TheU.S. 
Must Do More to Stop China's Encroachments. Foreing Affairs.

Kagan, R. (2007). End of Dreams, Return of History: International rivalry and American leadership. Policy Rewiev.

Kaplan, R. (2010, may/jun). The Geography of Chinese Power - How far can Beijing reach on land and sea? Foreing Affairs, 89(3), 22-41.

Kaplan, R. (2012). La Venganza de la Geografía, Cómo los mapas condicionan el destino de las naciones. (L. M. Dios, Trans.) Barcelona: RBA Libros S.A.

Krepinevich, A. J. (2015, Marzo/Abril). How to Deter China, The Case for Archipelagic Defense. Foreign Affairs, 94(2), 78-86.

Krepinevich, A., Watts, B., \& Work, R. (2003). Meeting the Anti-Access and Area-Denial Challenge. Washington: Center for Strategic and Budgetary Assessments.

Mackinder, H. J. (2010). El pivote geográfico de la historia. Geopolítica(s), 1(2), 301-319 .

Mahan, A. T. (1946). La influencia del Poder Naval en la Historia. Buenos Aires: Partenon.

Mearsheimer, J. J. (2001). The Tragedy of Great Power Politics. London: w.w. Norton and Company.

Morgenthau, H. (1987). La Politica entre las Naciones (6ta ed.). Grupo Editor Latinoamericano.

Poling, G. (2018, January). Why a South China Sea Diplomatic Breakthrough Is Unlikely:How to Respond to Beijing's Continued Military Buildup. Foreign Affairs.

Schweller, R. (1997). New Realist Research on Alliances: Refining, Not Refuting, Waltz' Balancing Proposition. American Political Science Review, 91(4).

Schweller, R. (2004). Unanswered Threats: A Neoclassical Realist Theory of Underbalancing. International Security, 29(2), 159-201.

Schweller, R. (2011). The future is uncertain and the end is always near. Cambridge Review of International Affairs, 24(2), 175-184.

Schweller, R. (2014). China's Aspirations and the Clash of Nationalisms in East Asia: A Neoclasical Realist Examination. International Journal of Korean Unification Studies, 23(2), 1-40.

Schweller, R., \& Pu, X. (2011). After Unipolarity, China's Visions of International Order in a Era of U.S. Decline. International Security, 36(1), 41-72.

State Council Information Office People's Republic of China. (2015). China's Military Strategy. Beijing.

Stratfor. (2014, noviembre). China Works to Assert its Dominance on the Seas.

Till, G. (1982). Estrategia Maritima y la Era Nuclear. Buenos Aires: Instituto de Publicaciones Navales.

Till, G. (2007). Poder Maritimo, una guia para el siglo XXI. Buenos Aires: Instituto de Publicaciones Navales.

Till, G. (2015, Autumn). The New USS Maritime Strategy, Another View from Outside. Naval 
Nuevas Dinámicas del Poder Naval en el Siglo XXI: la competencia por el control en el espacio marítimo (...) -(197- 211)

War College Review, 68(4), 34-45.

US Navy. (2015). A Cooperative Strategy for 21st Century Seapower. Washington DC US Navy. (2007). A Cooperative Strategy for 21st Century Seapower. Washington DC. 